\title{
2-bromo-1-(2-hydroxyphenyl)-3,4-dimethylpentan-1-one: A New Bromo-Compound with Stimulatory Activity Isolated from the Shed Leaves of Teak, (Tectona grandis L.)
}

\section{Suparna Mandal Biswas}

Agricultural and Ecological Research Unit, Indian Statistical Institute, 203, B.T. Road, Calcutta 700108, India

\section{ABSTRACT}

A new Bromo isotopic compound has been isolated and purified from the Methanol Fraction of Teak leaves (MFTk). Chromatographic and spectral analyses (TLC, UV, MS, NMR, and IR) indicated the compound to be 2-bromo-1-(2-hydroxyphenyl)-3,4dimethylpentan-1-one, in short, BrHPDMP with molecular wieghts 285 and 287. The whole leaf leachate of teak showed strong inhibitory activity in bioassay. But when fraction-4 (Methanolic fraction of teak leaf) was isolated and purified, it showed concentration dependent stimulatory activity on rice seeds. At 1000 ppm concentration, it showed $12.82 \%$ inhibition in shoot and $15.59 \%$ stimulation in root length. Below this concentration, it showed stimulatory effects on both shoot and root length. At $500 \mathrm{ppm}$, it revealed $10.04 \%$ stimulation in shoot length and $34.16 \%$ stimulation in root length. At a concentration of $31.25 \mathrm{ppm}$, it revealed maximum stimulatory effects i.e. $16.26 \%$ stimulation in shoot length and $42.78 \%$ stimulation in root length.

Key Words: teak (Tectona grandis L.), allelochemical, Bromo-compound, agroforestry species, growth stimulator.

Correspondence: S. M. Biswas. Address: Agricultural and Ecological Research Unit, Indian Statistical Institute, 203, B.T. Road, Calcutta 700 108, India. E-mail: suparna@isical.ac.in. Tel. No. (+91) (033) 2575 3220. Fax:(+91)(033) 25753049

DOI: $10.32945 /$ atr3414.2012 


\section{INTRODUCTION}

Natural plant products have growth regulatory as well as pharmaceutical properties. Plant allelochemicals as biopesticides and growth promoters is an important emerging area of study. Since most of the allelochemicals are known to be toxic to a variety of weeds and pests, they might be exploited as natural pesticides (Miles et al., 1993). Synthetic agrochemicals are advocated for management of plant diseases but application of these only provide short-term measures as they are reported to induce new strains of pathogens. At the same time, they are also known for their severe environmental hazards. Biological control techniques on the other hand, are a pollution free and economical option to fight pathogens in agricultural ecosystems. Natural agrochemicals are effective, quickly biodegradable and leave no toxic residue (Khanh et al., 2005). Moreover, there is an increasing demand for organically produced and pesticide residue-free food in both international and local markets. The development of natural products such as herbicides, fungicides, and their role in biological control of plant diseases indicates a reduction in environmental and health hazards. Allelopathic properties of plants can be exploited successfully for both management of crops via adopting suitable crop rotation (Anaya, 1990) and development of more potent natural agrochemicals based on the identified chemical moieties (Inderjit and Mukerji, 2006). The teak tree is well known to release various inhibitors via its roots continuously from seedling stage until maturity and even after degradation of mature tree leaves.

Teak (Tectona grandis $\mathrm{L}$ )) is one of the most important artificial forest trees in India and also the source of one of the most valuable wood (Betancourt, 1983). This tree sheds huge amounts of leaves, covering the ground with a very thick layer of the large leaves, offering a physical barrier to young seedlings. During rainy reason, large volumes of allelochemicals from these leaves leach into the soil. Since allelochemicals are organic carbon rich compound, they stimulate microbial activity in the soil. This tree has also been successfully used in agroforestry systems and in crop rotation in India, Costa Rica, Venezuela and Cuba (Jacoby and Darrigo, 1990). In an earlier work, we found the presence of two inhibitors and two stimulators in the leaf leachate of Teak (Mandal and Brahmachary, 1998). We identified one inhibitory compound,3, 4 benzyl ester derivative from leaves of Tectona grandis L. (Biswas et al., 2009). We are therefore interested to isolate and identify the stimulatory compound from Teak 
leaves. Our present study deals with the isolation and molecular elucidation and bioefficacy of stimulatory allelochemicals in shed leaves of teak.

\section{MATERIALS AND METHODS}

\section{Bioassay with Teakleafleachate}

Aqueous leaf leachates were prepared by soaking 10 gm of dry leaves (collected from the forest floor) in $20 \mathrm{~mL}$ distilled water for 1 day. It was filtered through filter paper (whatman 1) and the filtrate made up to $25 \mathrm{ml}$. This constituted the standard or stock solution (1:2.5), from which $1: 5$ and $1: 10$ dilutions were made. Effects of teak leaf leachate on germination and seedling growth of rice were detected by bioassay (Mandal and Tapaswi, 1999). Rice seeds were surface sterilized with $0.1 \%$ mercuric chloride solution, washed with distilled water and placed on a filter paper in a Petridish. A negative control was maintained by treatment with equal volumes of distilled water (instead of treated solution). After 4 days, shoot length and root length in the control and treated sets were measured.

\section{Isolation and Characterization of Active Allelochemical}

Teak (Tectona grandis L.) leaves (200gm) were dried and powdered using sample miller machine (Cyclotec 1093 Sample Mill, TECATOR) and then soaked in $500 \mathrm{ml}$ of methanol. The entire mixture was then vortexed in high speed (3000 rpm) using a mechanical stirrer (Model No. DC Stirrer NZ-1000s AC220V, EYELA) for 1 hour and then filtered through sintered disc funnel. The brown colored extract was collected and concentrated in a rotary vacuum evaporator (EYELA, Model No. N1-NW) and subsequently extracted with hexane, ethyl acetate, acetone and methanol respectively (Flow Diagram 1). Finally the extracts were purified by column chromatography and thin layer chromatography. Here we put emphasis on the Methanol fraction of Teak (henceforth referred to as MFTk) for biological activity.

\section{Thin Layer Chromatography}

Cellulose powder was used as coating material for analysis of polar fractions of Teak (MFTk). TLC plates $(20 \times 20 \mathrm{~cm})$ were employed for this 


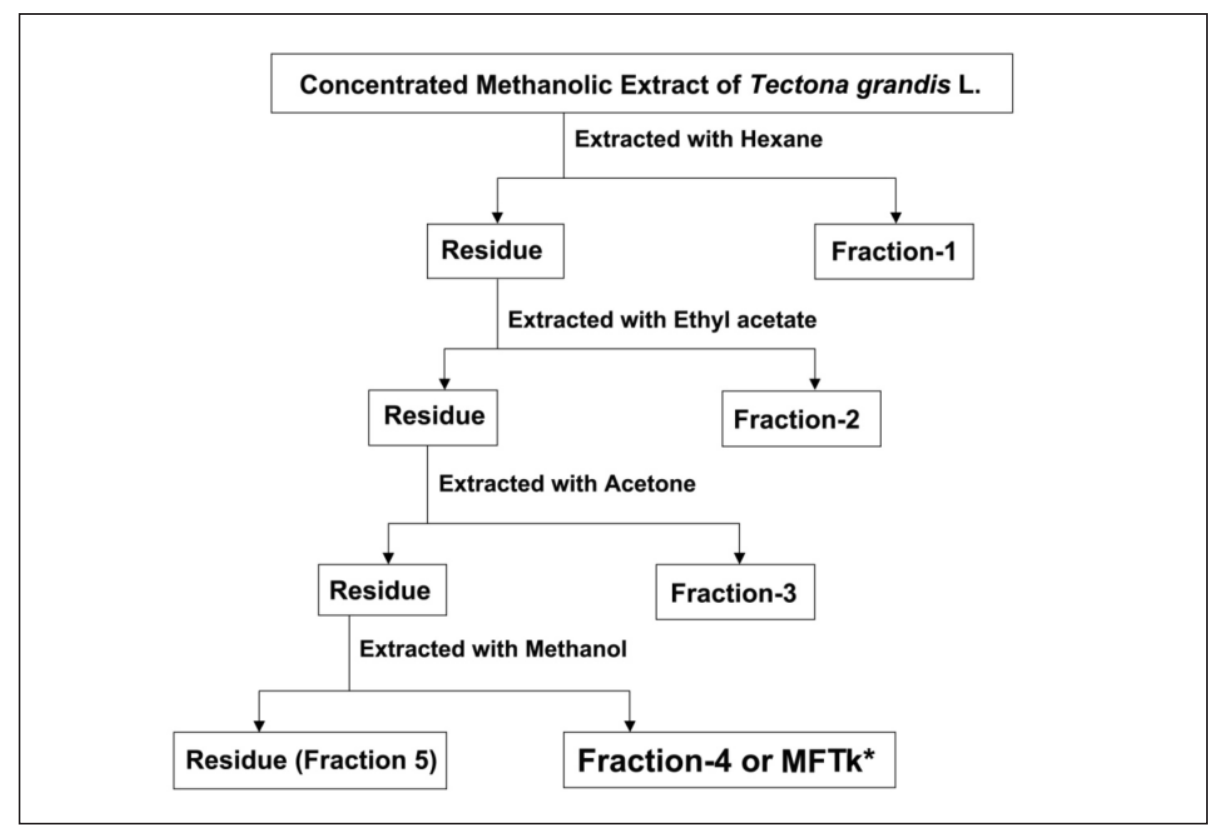

Figure 1. Schematic representation of extraction compound from the concentrated methanolic extract of Tectona grandis $L$.

study. The plates were coated uniformly with a $0.5 \mathrm{~mm}$ layer of silica gel G. Samples of $20 \mu$ solution were loaded (500ppm) and developed up to $18 \mathrm{~cm}$ in a glass chamber pre-saturated with solvent system (Methanol : acetone:: $5: 95)$ and dried immediately (Stahl, 1969). Finally the spots were detected by exposing plates under iodine vapor and under UV light $(365 \mathrm{~nm})$.

\section{Spectralanalysis}

MS Analysis for determination of molecular weight of the purified MFTk was done with Mass Spectrometer (Micromass Q-TOF Micro ${ }^{\mathrm{TM}}$ ) on positive ion mode.

1HNMR and CNMR analyses were obtained using $500 \mathrm{MHz}$ NMR Spectrometer (MODEL: DRX 500, MFGD. BRUKER). 1HNMR spectra of MFTk were recorded on ppm (0-10) scale with end of sweep at 0 ppm by pulse programme Zg and number of scan 64. Tetramethyl silane (TMS) was used as standard marker, producing a sharp peak at 0 ppm. For $13 \mathrm{C}$ analysis Zgdc pulse programme with number of scan IK (1024) was utilized. 13C -NMR spectra of MFTk were also recorded on ppm (0-200) 
scale with end sweep at $0 \mathrm{ppm}$. In both cases, samples were analyzed at ambient temperature and $\mathrm{CDCl} 3$ was used as solvent for dissolving the compound.

IR (Spectrometer JASCO-SP-Model No. 410) analysis was used to confirm the important functional group in the extracted and purified MFTk. Solid-state spectrum was obtained by mixing the required quantity of sample in $\mathrm{KBr}$ plate.

\section{Effects of MFTk on the germination and subsequentgrowth of rice}

The allelopathic potentials of purified MFTk on the germination and seedling growth of rice was determined by Laboratory bioassay experiments. Experiments were laid out in replicated Petri plates $(90 \mathrm{~mm}$ dia) containing a layer of filter papers. $30 \mathrm{mg}$ of MFTk was dissolved in $30 \mathrm{ml}$ of distilled water. This constituted the stock solution of $1000 \mathrm{ppm}$, from which further dilutions 500, 250, 125, 62.5, 31.25, 15.62, 7.81ppm were made. Nine sets of experiments were performed, including the control. In the control set, $15 \mathrm{~mL}$ of distilled water was added instead of treated solution. Seeds were surface sterilized with $0.1 \%$ mercuric chloride solution, washed with distilled water and placed on a filter paper on a Petri dish. After 4 days, shoot length and root length in the control and treated sets were measured (Mandal, 2001).

\section{RESULTS AND DISCUSSION}

\section{Leafleachate Bioassay}

One-daysoaked leaf leachate of teak at $1: 2.5,1: 5$ and $1: 10$ dilutions showed strong inhibitory activity on both shoot and root length. Shoot lengths were inhibited by $73-81 \%$ and root length were inhibited by $94-$ 97\% (Figure 1).

\section{Isolation and Characterization of Active Allelochemical}

\section{TLCAnalysis}

After purification, MFTk was run on TLC in the solvent system Methanol : Acetone : 5 : 95 . A single bright yellow spot with Rf value 0.84 in iodine vapor and violet spot under UV light (365nm) was observed. 


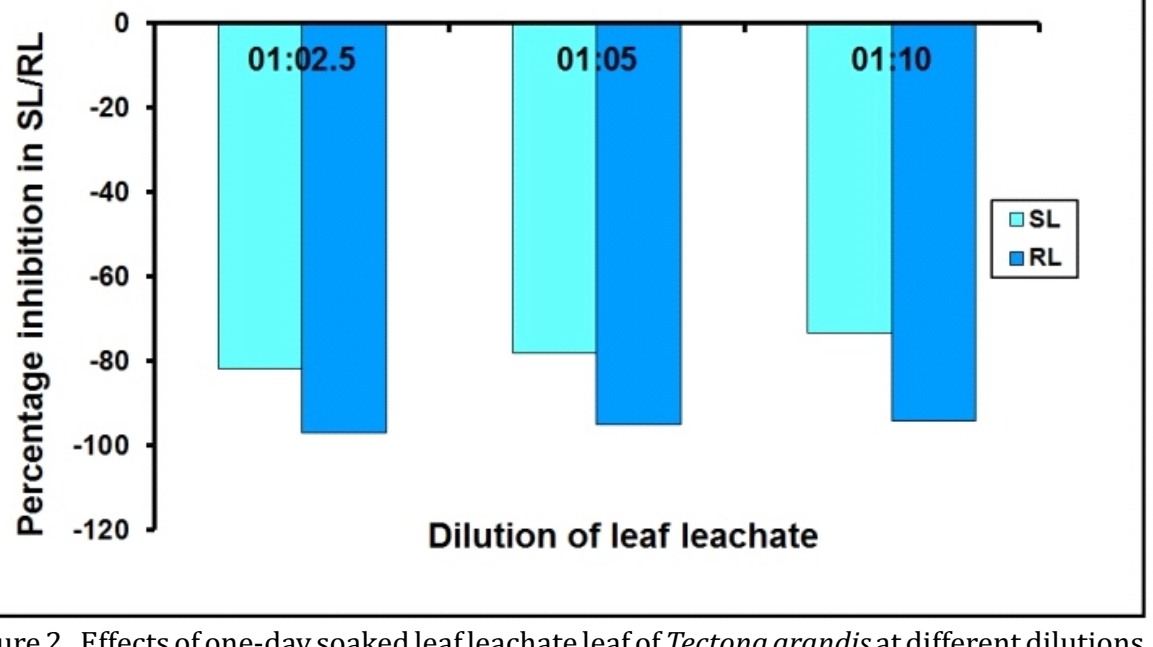

Figure 2. Effects of one-day soaked leafleachate leaf of Tectona grandis at different dilutions on germination and seedling growth of rice. Correlation is significant at 0.5 levels (Pearson 2-Tailed).

In the MS spectrum, 286 and 288 peaks indicate the molecular weight of material plus hydrogen $(\mathrm{M}+\mathrm{H})+$ and 308 and 310 peaks indicate the molecular weight of the material plus sodium $(\mathrm{M}+\mathrm{Na})$ - (Figure 2). A compound that contains one bromine atom will have an $\mathrm{M}+2$ peak almost equal in intensity to the molecular ion containing $81 \mathrm{Br}$ isotope (Silverstein et al., 1997).

\section{Spectral Analysis}

1HNMR peak at $7.27,7.72,7.53$ and $8.00 \mathrm{ppm}$ indicated the $\mathrm{CH}$ of the benzene ring (Figure 3).Peak at 5.0ppm suggested aromatic C-OH. Peak at 4.32ppm supported the aliphatic $\mathrm{CH}$ in respect to position of the $\mathrm{Br}$ and Peak at $3.66 \mathrm{ppm}$ indicated $\mathrm{CH}$ in respect to position of the Br. Peak at 1.29, 1.29 and 1.28ppm indicated the presence of three $\mathrm{CH}_{3}$.

The ${ }^{13} \mathrm{C}$ peak at $191 \mathrm{ppm}$ showed the presence of a carbonyl group (Figure 4a). Peaks at $\delta 139.67,130.62,124.71,121.42$ and $114.46 \mathrm{ppm}$ are due to the other carbons of the aromatic ring. In this compound there are three $\mathrm{CH}_{3}$ at $\delta 20.42,20.24$ and14.51ppm as evident from the Dept-135 Spectra (Figure $4 \mathrm{~b}$ ). Dept-90 spectra indicated the presence of seven $\mathrm{CH}$ at $\delta 139.66,130.62,124.70,121.41,114.46,43.22,30.10 \mathrm{ppm}$ (Figure 4c). 


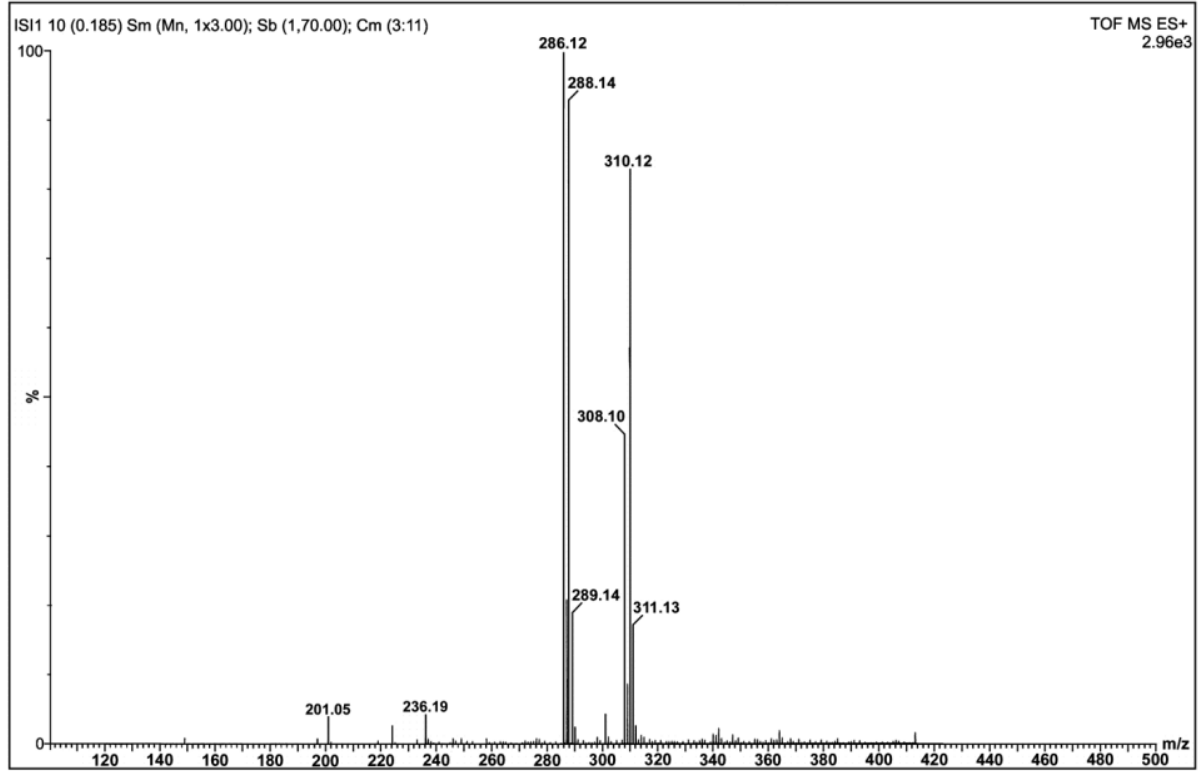

Figure 2. MS spectra of the purified MFTk of Tectona grandis $L$.

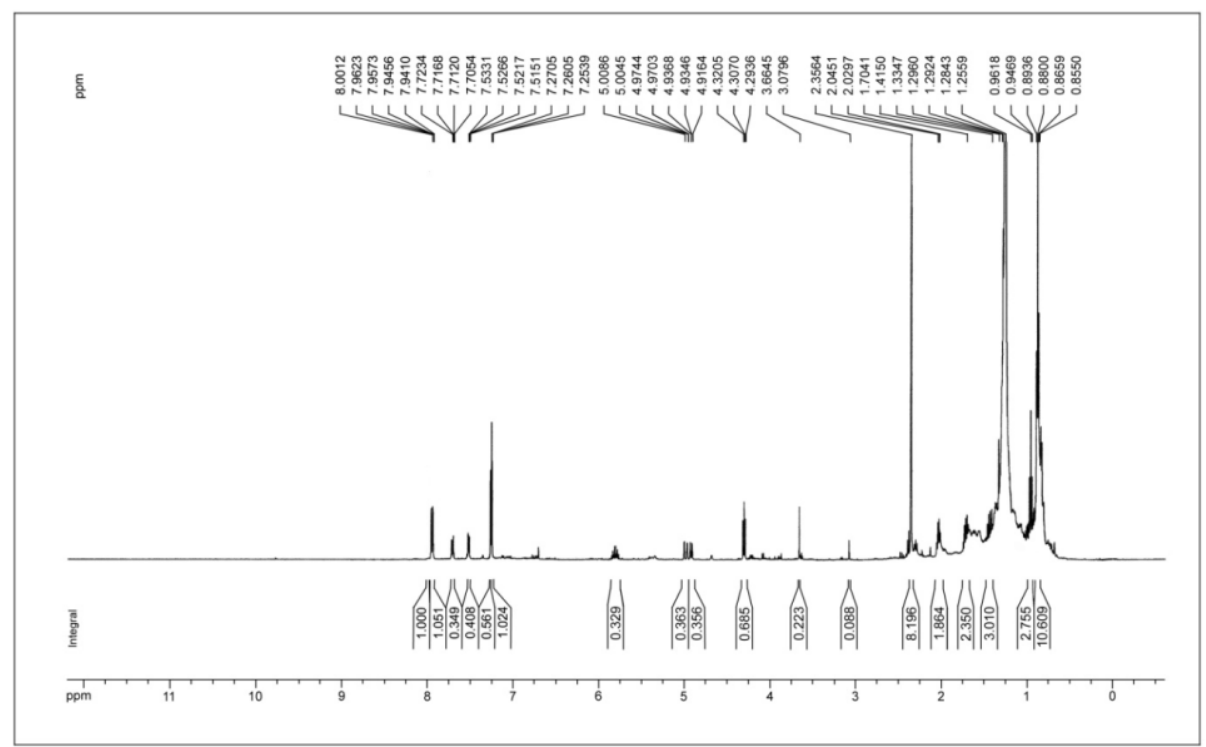

Figure 3. ${ }^{1}$ HNMR Spectra of the purified MFTk of Tectona grandis $L$. 
Peak at $163.41 \mathrm{ppm}$ indicated the aromatic $\mathrm{C}-\mathrm{OH}$. Peak at $65.97 \mathrm{ppm}$ indicated the presence of $\mathrm{CH}$ in respect to position of the $\mathrm{Br}$ and peak at 43.22 ppm is due to $\mathrm{CH}$ in respect to the position of the $\mathrm{Br}$.

IR Spectra of purified MFTk showed Peak at $3392 \mathrm{~cm}^{-1}$ region with strong and broad absorption, which indicated the intermolecular $\mathrm{OH}$ stretching vibrations of the compound (Figure 5). Peak at 2929 and 2853 $\mathrm{cm}^{-1}$ resulted from the asymmetrical $\left({ }_{a s} \mathrm{CH}_{2}\right)$ and symmetrical stretching $\left(_{\mathrm{s}}\right.$ $\mathrm{CH}_{2}$ ) of methylene group respectively. Peak at $1722 \mathrm{~cm}^{-1}$ supported the $\mathrm{C}=0$ stretching vibrations. Peak at $810 \mathrm{~cm}^{-1}$ strongly suggested the presence of benzene ring in the compound. A strong $\mathrm{CH}_{2}$ wagging band is observed for the $\mathrm{CH}_{2} \mathrm{Br}$ group at $1248 \mathrm{~cm}^{-1}$ region. (Silverstein et al., 1997).

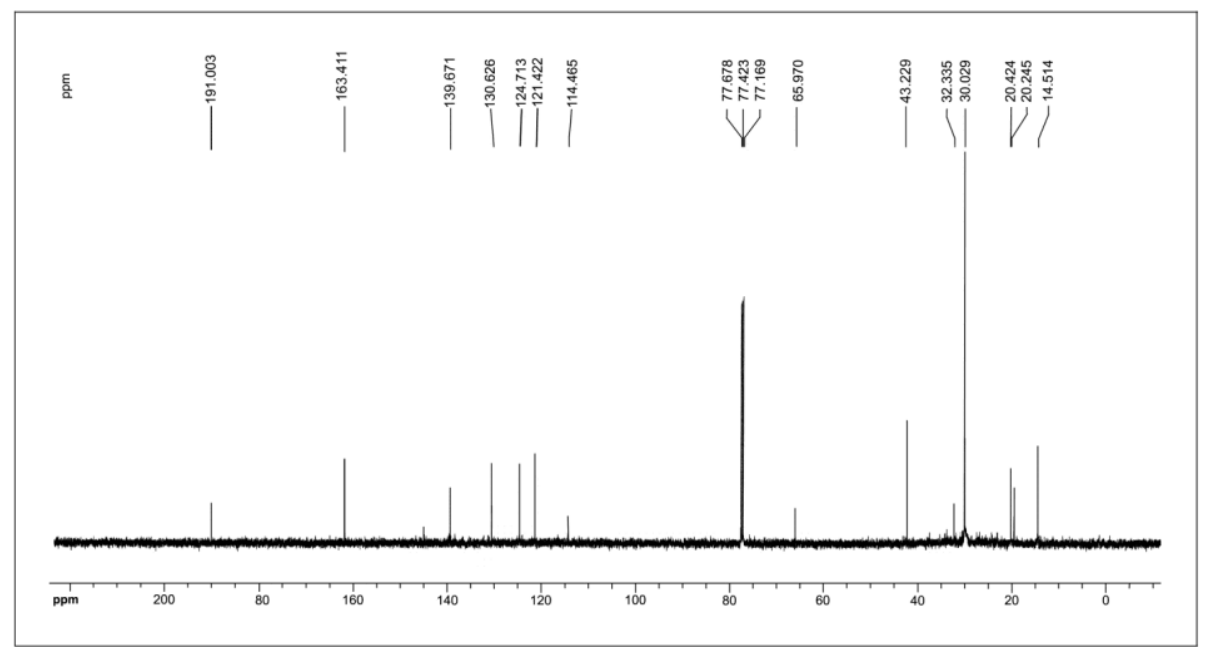

Figure 4a. ${ }^{13}$ CNMR Spectra of the purified MFTk of Tectona grandis $L$.

Spectral Analysis

${ }^{1} \mathrm{HNMR}$ peak at $7.27,7.72,7.53$ and $8.00 \mathrm{ppm}$ indicated the $\mathrm{CH}$ of the benzene ring (Figure 3). Peak at 5.0ppm suggested aromatic C-OH. Peak at 4.32ppm supported the aliphatic $\mathrm{CH}$ in respect to position of the $\mathrm{Br}$ and Peak at 3.66ppmindicated $\mathrm{CH}$ in respect to position of the Br. Peak at 1.29, 1.29 and $1.28 \mathrm{ppm}$ indicated the presence of three $\mathrm{Ch}_{3}$.

The ${ }^{13} \mathrm{C}$ peak at $191 \mathrm{ppm}$ showed the presence of a carbonyl group (Figure 4a). Peaks at $\delta 139.67,130.62,124.71,121.42$ and $114.46 \mathrm{ppm}$ are due to the other carbons of the aromatic ring. In this compound there are three $\mathrm{CH}_{3}$ at $\delta 20.42,20.24$ and14.51ppm as evident from the Dept-135 


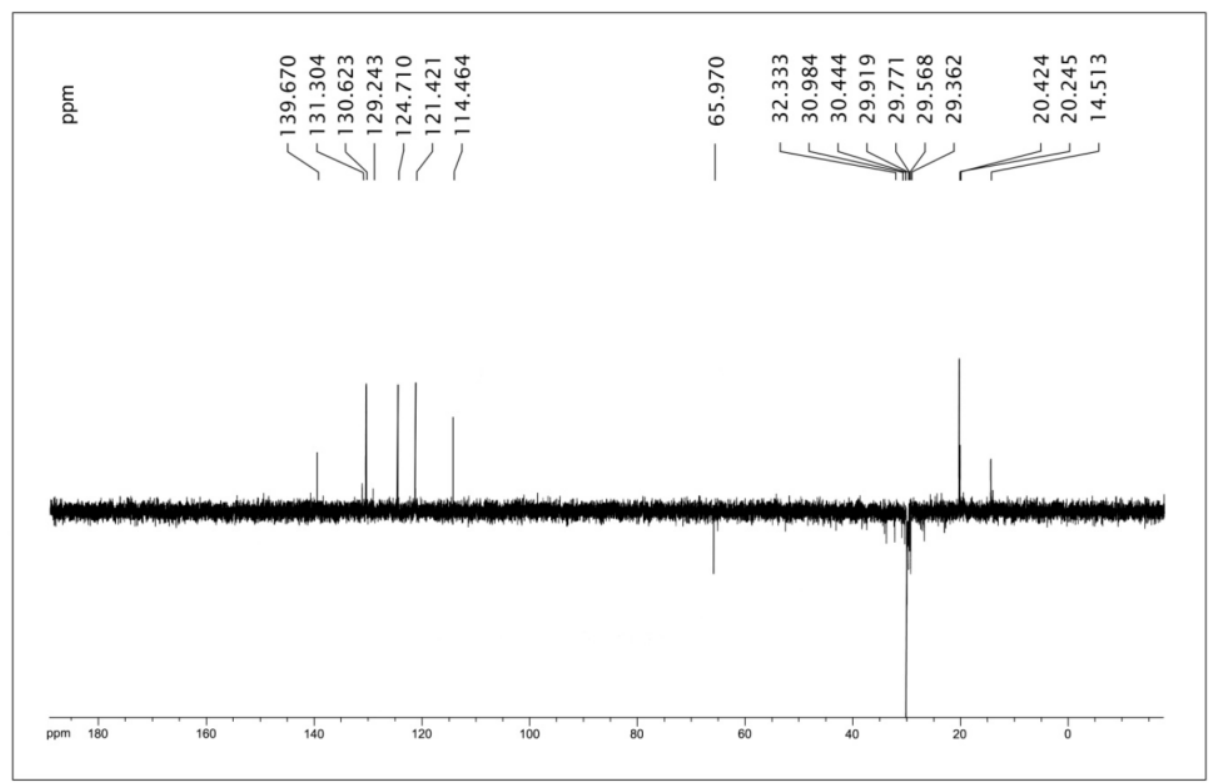

Figure 4b. Dept-35 Spectra of purified MFTk of Tectona grandis $L$.

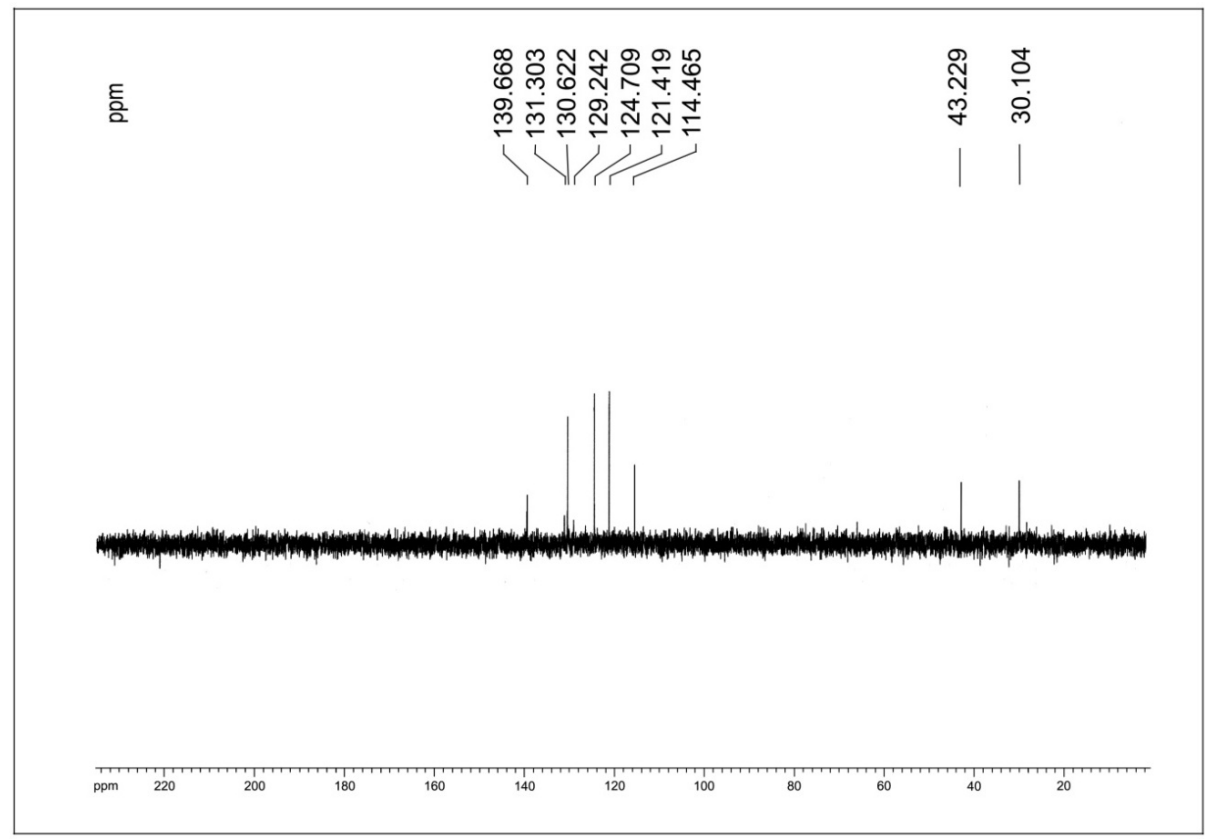

Figure 4c. Dept-90 Spectra of purified MFTk of Tectona grandis $L$. 
Spectra (Figure 4b). Dept-90 spectra indicated the presence of seven $\mathrm{CH}$ at $\delta$ 139.66, 130.62, 124.70, 121.41, 114.46, 43.22, 30.10ppm (Figure 4c). Peak at $163.41 \mathrm{ppm}$ indicated the aromatic $\mathrm{C}-\mathrm{OH}$. Peak at $65.97 \mathrm{ppm}$ indicated the presence of $\mathrm{CH}$ in respect to position of the $\mathrm{Br}$ and peak at $43.22 \mathrm{ppm}$ is due to $\mathrm{CH}$ in respect to the position of the $\mathrm{Br}$.

IR Spectra of purified MFTk showed Peak at $3392 \mathrm{~cm}^{-1}$ region with strong and broad absorption, which indicated the intermolecular $0-\mathrm{H}$ stretching vibrations of the compound (Figure 5). Peak at 2929 and 2853 $\mathrm{cm}^{-1}$ resulted from the asymmetrical $\left({ }_{\text {as }}^{\mathrm{V}} \mathrm{CH}_{2}\right)$ and symmetrical stretching $\left({ }_{\mathrm{s}}^{\mathrm{v}} \mathrm{CH}_{2}\right)$ of methylene group respectively. Peak at $1722 \mathrm{~cm}^{-1}$ supported the $\mathrm{C}=0$ stretching vibrations. Peak at $810 \mathrm{~cm}^{-1}$ strongly suggested the presence of benzene ring in the compound. A strong $\mathrm{CH}_{2}$ wagging band is observed for the $\mathrm{CH}_{2} \mathrm{Br}$ group at $1248 \mathrm{~cm}^{-1}$ region. (Silverstein et al., 1997).

Chromatographic and spectral analyses of MFTk revealed that the compound is 2-bromo-1-(2-hydroxyphenyl)-3,4-dimethylpentan-1-one

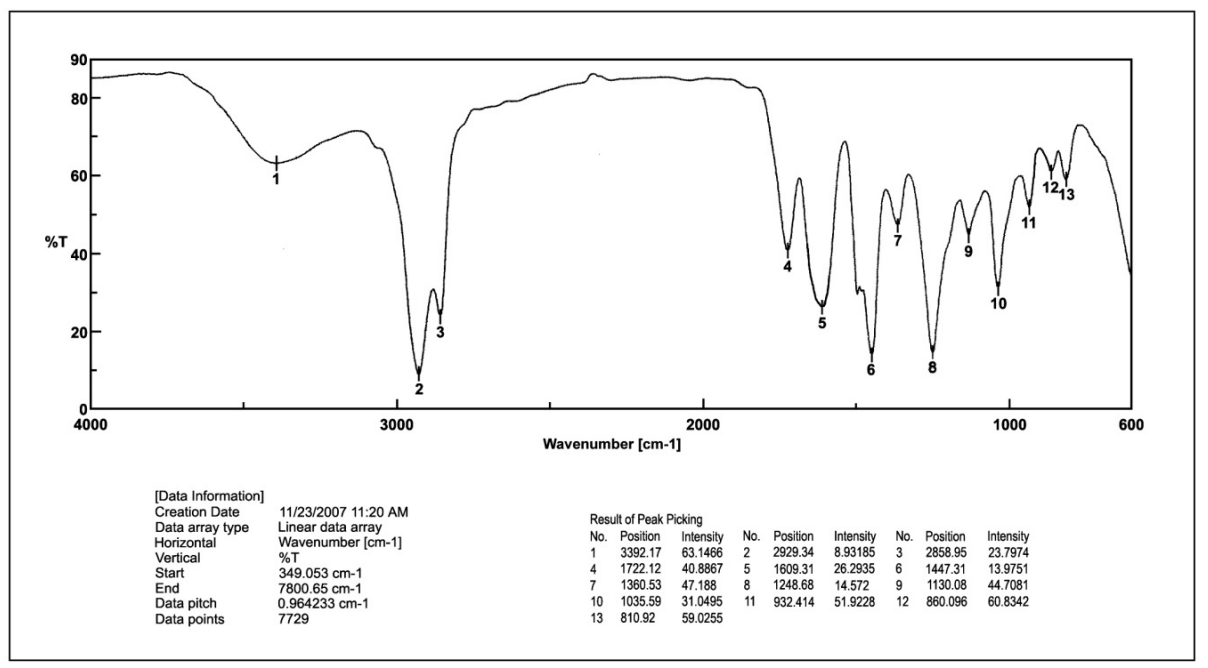

Figure 5. Dept-35 Spectra of purified MFTk of Tectona grandis $L$.

(BrHPDMP) or bromoisotope (Figure 6). In fact, there are no reports on the presence of 2-bromo-1-(2-hydroxyphenyl)-3,4-dimethylpentan-1-one in Tectonagrandis. 


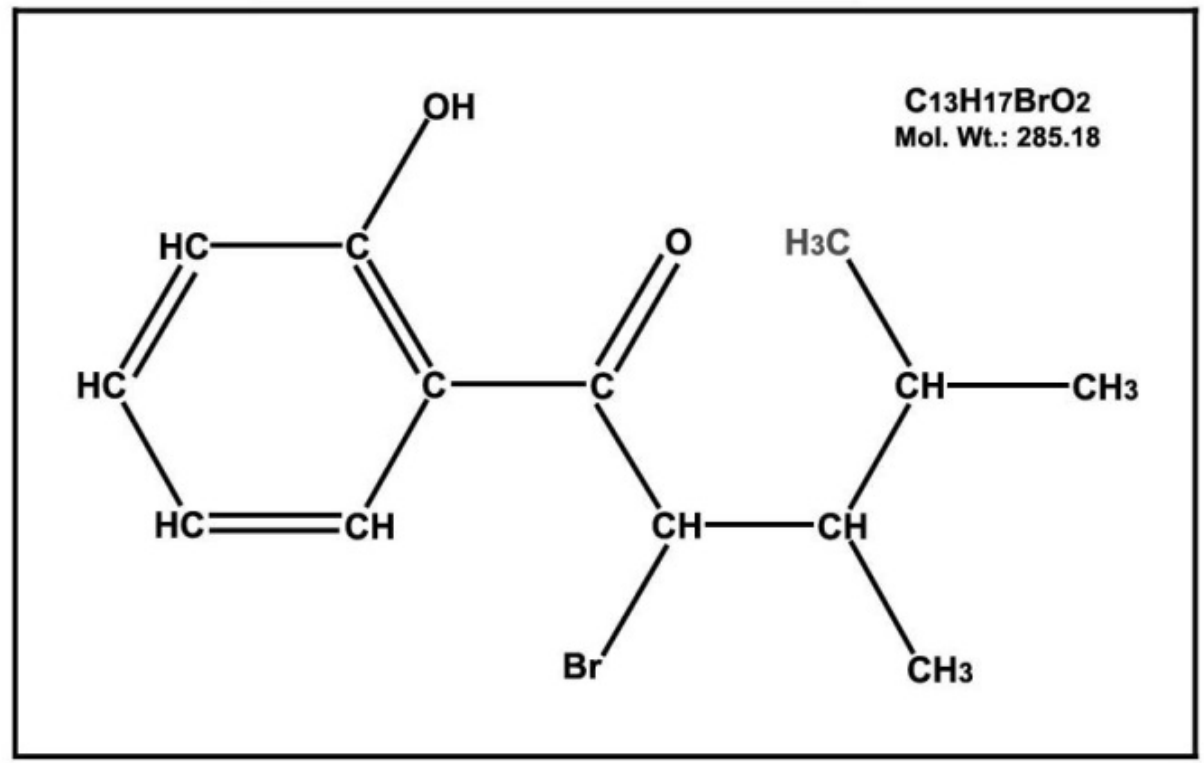

Figure 6. Molecular structure of 2-Bromo-1-(2-hydroxyphenyl-3,4-dimethylpentane-1one of Tectona grandis $L$.

Effects of MFTk on the germination and subsequent growth of rice

The fraction-4 of teak (MFTk) showed concentration-dependent stimulatory activity on rice seeds. At $1000 \mathrm{ppm}$ concentration it showed $12.82 \%$ inhibition in shoot and $15.59 \%$ stimulation in root length. Below this concentration it showed stimulatory effects on both shoot length and root length. At 500ppm it revealed $10.04 \%$ inhibition in shoot length and $34.16 \%$ stimulation in root length. At $31.25 \mathrm{ppm}$ it revealed maximum stimulatory effects i.e. $16.26 \%$ stimulation in shoot length and $42.78 \%$ stimulation in root length. Fraction-4 or TKM showed greater stimulatory activity in shoot length than root length (Figure 7).

As teak trees shed an enormous amount of large leaves which form a thick carpet on the forest floor, the leachates of these leaves are worth studying. A new bromo isotope with stimulatory activity has been isolated and purified from the Methanol Fraction (MFTk) of teak leaves. Chromatographic and spectral analyses of MFTk revealed that the compound is 2-bromo-1-(2-hydroxyphenyl)-3,4-dimethylpentan-1one,BrHPDMP) or bromo-hydroxyphenyl-dimethylpentan. There are no reports on the presence of bromo-hydroxyphenyl-dimethylpentan in Teak, 


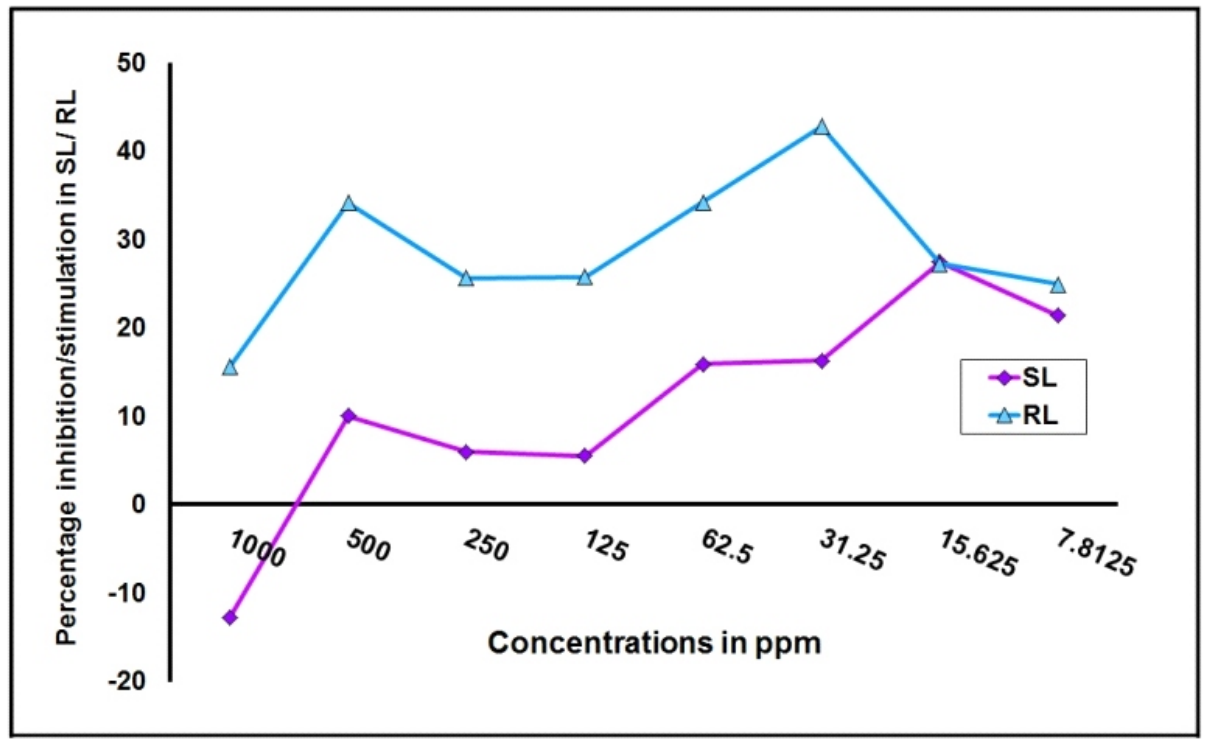

Figure 7. Effects MFTk of Tectona grandis L. at different concentrations on germination and seeding growth of rice. Correlation is significant at 0.05 levels (Pearson 2tailed).

however, Khan and Mlungwana (1999) reported 5-Hydroxylapachol, a cytotoxic agent from Tectona grandis. Due to its stimulatory activity, it can be presumed that this compound may be used as biofertilizer in Agricultural practices. Within the forest ecosystem allelochemical interactions play a much greater role than previously thought, affecting growth, germination, plant succession, and vegetative patterning (Jacoby and D'arrigo, 1990). The results prove that higher woody species like Teak may also exert marked effects on the ecosystem through the leaf leachate. More research is needed on the beneficial aspects of allelopathy in the forest ecosystem

\section{CONCLUSION}

A novel as well as unusual type of bromo isotopes,2-bromo-1-(2hydroxyphenyl)-3,4-dimethylpentan-1-one (BrHPDMP) or bromohydroxyphenyl-dimethylpentan) with stimulatory activity was detected in the methanolic fraction of teak leaves (TKM). The whole leaf leachate of teak showed strong inhibitory activity in bioassay, but when TK-M was isolated and purified, it showed concentration-dependent stimulatory and 
inhibitory activity on rice seeds. Due to this stimulatory activity, it can be presumed that this allelochemical may be used as biofertilizer in agricultural practices and the teak plant would be a useful agroforestry species in Agroecosystems.

\section{ACKNOWLEDGMENT}

I am privileged to convey our sincere gratitude to our respected Director, Prof. Bimal Roy, Indian Statistical Institute, for providing Laboratory facilities and financial support. We are indebted to Prof. Anjana Dewanjii, Professor-in-Charge and Head of the Biological Sciences Division, Agricultural and Ecological Research Unit, Indian Statistical Institute, for her affectionate encouragement, valuable advice and enormous laboratory facilities. We also thank Miss Barnali Das, Mrs Jaba Mukherjee, Mr Bharat Bhanderi, Mr Nityananda Banik and Mr. Laxman Magranti of Agricultural and Ecological Research Unit of the Indian Statistical Institute, for their valuable assistance in laboratory and field.

\section{REFERENCES}

ANAYA A. L., M. R. CALERA, R. MATA and R. P. MIRANDA. 1990. Allelopathic potential of compounds isolated from Ipomoea tricolor Cav. (Convolvulaceae).Journal of Chemical Ecology 16: 2415-2152.

BETANCOURT, B. A. 1983. Silvicultura especial de arboles maderables tropicales. Editorial Cientifico - Tecnica. La Habana, pp. 342-345.

BISWAS, S.M., S. BHATTACHARYA, S. CHANDA and L. KUMAR. 2009. 3, 4 dihydroxy benzyl ester derivative, a potent biopesticide isolated from leaves of Tectona grandis L. Biopesticide International 5: 58-69.

INDERJIT and K. M. MUKERJI. 2006. Allelochemicals: Biological Control of Plant Pathogens and Diseases, KG, Eds, Springer, Dordrecht, Netherlands.

KHANH T. D., I. M. CHUNG, T. D. XUAN and S. TAWATA. 2005. The exploitation of crop allelopathy in sustainable agricultural production. Journal of Agronomy and Crop Science 191: 172-184. 
KHAN, R.M. and S.M. MLUNGWANA. 1999. 5-Hydroxylapachol: a cytotoxic agent from Tectona grandis. Phytochemistry 50: 439-442.

KONAR, J. and D.P. KUSHARI. 1989. Effect of Leaf Leachate of Four Species on Sprouting Behavior of Rhizomes, Seedling Growth and Diosgenin Content of Costus speciosus. Bulletin of the Torrey Botanical Club 116: 339-343.

MANDAL, S. and R.L. BRAHMACHARY. 1998. Growth stimulators in shed leaves of Teak (Tectona grandis). The Indian Forester 124: 267-269.

MANDAL S. and P.K. TAPASWI. 1999. Phytotoxicity of Aqueous Leachate from the Weed, Crozophora rottleri A. Juss. On Rice, Wheat and Mustard.J. Weed. Sci. Tech. 44: 144-146.

MANDAL S. 2001. Allelpathic activity of root exudates from Leonurus sibiricus L. (Raktodrone). Weed Biology and Management 1: 170-175.

MILES D.H., V. CHITTAWANG, HEDIN and U. KOKPOL. 1993. Potential agrochemicals from leaves of Wedelia biflora. Phytochemistry 32:1 427-1430.

SILVERSTEIN R. M, WEBSTER F. X and DAVID J. KIEMLE. 1997. Spectrometric identification of organic compound 6th Edn. John Wiley \& Sons, New York.

STAHL E.1969. Thin Layer Chromatography. Academic Press, London. 